\title{
BMJ Open Impact of the COVID-19 pandemic on transplantation by income level and cumulative COVID-19 incidence: a multinational survey study
}

\author{
Shaifali Sandal (D , ${ }^{1,2}$ Allan Massie, ${ }^{3}$ Brian Boyarsky, ${ }^{4}$ Teresa Po-Yu Chiang, ${ }^{4}$ \\ Kednapa Thavorn, ${ }^{5,6}$ Dorry L Segev, ${ }^{3,4}$ Marcelo Cantarovich (D) 1,2
}

To cite: Sandal S, Massie A, Boyarsky B, et al. Impact of the COVID-19 pandemic on transplantation by income level and cumulative COVID-19 incidence: a multinational survey study. BMJ Open 2022;12:e055367. doi:10.1136/ bmjopen-2021-055367

- Prepublication history and additional supplemental material for this paper are available online. To view these files, please visit the journal online (http://dx.doi.org/10.1136/ bmjopen-2021-055367).

Received 12 July 2021 Accepted 21 December 2021

A) Check for updates

(c) Author(s) (or their employer(s)) 2022. Re-use permitted under CC BY-NC. No commercial re-use. See rights and permissions. Published by BMJ.

For numbered affiliations see end of article.

Correspondence to Dr Marcelo Cantarovich; marcelo.cantarovich@muhc. mcgill.ca

\section{ABSTRACT}

Objectives The COVID-19 pandemic significantly affected the provisions of health services to necessary but deprioritised fields, such as transplantation. Many programmes had to ramp-down their activity, which may significantly affect transplant volumes. We aimed to pragmatically analyse measures of transplant activity and compare them by a country's income level and cumulative COVID-19 incidence (CCI).

Design, setting and participants From June to September 2020, we surveyed transplant physicians identified as key informants in their programmes. Of the 1267 eligible physicians, $40.5 \%$ from 71 countries participated.

Outcome Four pragmatic measures of transplant activity. Results Overall, $46.5 \%$ of the programmes from highincome countries anticipate being able to maintain $>75 \%$ of their transplant volume compared with $31.6 \%$ of the programmes from upper-middle-income countries, and with $21.7 \%$ from low/lower-middle-income countries $(p<0.001)$. This could be because more programmes in high-income countries reported being able to perform transplantation/s (86.8\%\%-58.5\%-67.9\%, $\mathrm{p}<0.001)$, maintain prepandemic deceased donor offers $(31.0 \% \%-14.2 \%-26.4 \%, p<0.01)$ and avoid a ramp down phase $(30.9 \% \%-19.7 \%-8.3 \%$, $\mathrm{p}<0.001$ ), respectively. In a multivariable analysis that adjusted for $\mathrm{CCl}$, programmes in upper-middle-income countries (adjusted $\mathrm{OR}, \mathrm{aOR}=0.47,95 \% \mathrm{Cl} 0.27$ to 0.81 ) and low/lower-middle-income countries (aOR $0.33,95 \% \mathrm{Cl} 0.16$ to 0.67 ) had lower odds of being able to maintain $>75 \%$ of their transplant volume, compared with programmes in high-income countries. Again, this could be attributed to lower-income being associated with 3.3-3.9 higher odds of performing no transplantation $/ \mathrm{s}, 66 \%-68 \%$ lower odds of maintaining prepandemic donor offers and $37 \%-76 \%$ lower odds of avoiding ramp-down of transplantation. Overall, CCI was not associated with these measures.

Conclusions The impact of the pandemic on transplantation was more in lower-income countries, independent of the COVID-19 burden. Given the lag of $1-2$ years in objective data being reported by global registries, our findings may inform practice and policy. Transplant programmes in lower-income countries may need more effort to rebuild disrupted services and recuperate from the pandemic even if their COVID-19 burden was low.
Strengths and limitations of this study

- This study pragmatically analysed four measures of transplant activity to capture the state of transplantation globally.

- Responses were compared by a country's income level and cumulative COVID-19 incidence.

- We were able to mobilise transplant leadership from 71 different countries to take our survey and attain a good response rate amid a pandemic.

- The income level of a country is a surrogate measure of the vulnerabilities of a healthcare system.

- We could not obtain adequate representation from certain regions, such as East Asia and Africa.

\section{INTRODUCTION}

The COVID-19 pandemic has globally impacted and overwhelmed healthcare systems and as a consequence, non-COVID medical fields have suffered significant collateral harm; ${ }^{1-3}$ this includes the field of solid organ transplantation. Following the WHO announcement declaring COVID-19 a pandemic, many transplant programmes reported cutting down on their activity due to multiple reasons. ${ }^{4-7}$ There was a redirection of services and resources to COVID-related care, lower procurement of organs from deceased donors, and cancellation of non-urgent surgeries, such as living donor transplantations. ${ }^{8-11}$ Also, there were initial concerns that transplant recipients with COVID-19 are at a higher risk of adverse outcomes. ${ }^{12-17}$ Management of immunosuppressive medications in transplant recipients and the pathogenesis of the SARS-CoV-2 in an immunosuppressed host were also largely unclear. $^{18}$ Thus, as a precautionary measure, many centres closed their transplant programmes or cut down on their activity. ${ }^{9} 10$ This phase was referred to as the 'ramp-down' phase. 


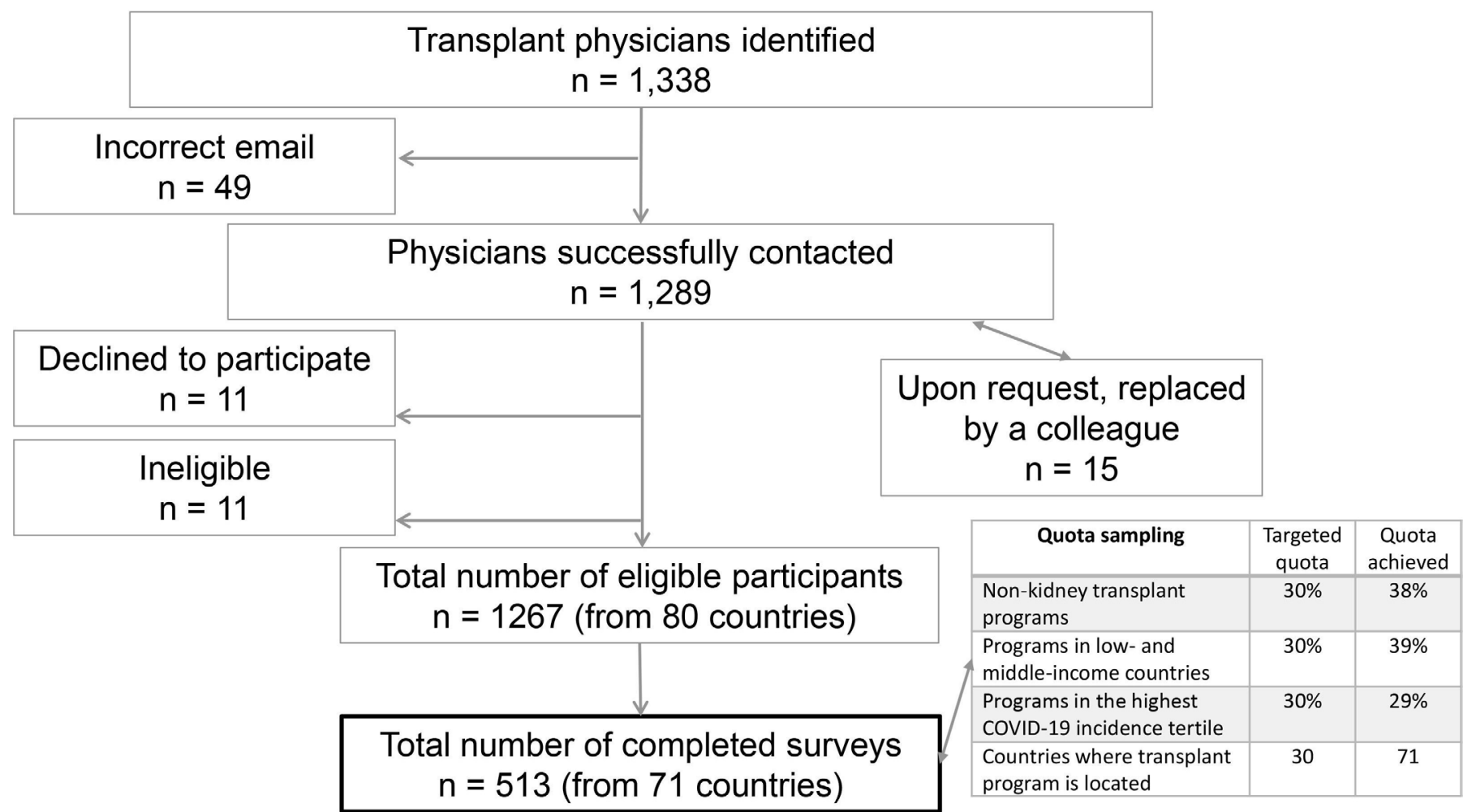

Figure 1 Study flow diagram.

Evidence from the initial weeks showed a substantial decrease in measures of transplant activity. ${ }^{4-7} 19$ For example, the overall reduction in deceased donor transplantation was $90.6 \%$ in France, and $51.1 \%$ in the USA. ${ }^{4}$ Following this, some studies reported that the burden of COVID-19 was a major determinant of some of these measures of activity. ${ }^{5}{ }^{20}$ However, much of this work came from resource-rich countries that also reported a high burden of COVID-19. Transplant leadership initially recommended that resource-poor countries prioritise efforts towards resolving the pandemic. ${ }^{11} 21$ Thus, it remains to be seen if the impact of the pandemic to transplantation varied in regions with lower baseline healthcare resources and higher health system vulnerabilities.

Responses to and decision making during global threats, such as a pandemic, are influenced by a country's baseline healthcare systems. ${ }^{82-24}$ A country's wealth or income level, as defined by the World Bank, provides a surrogate measure for a country's expenditure in health and the ability to cope with the social and economic disruption caused by a global threat. $^{23-27}$ Prepandemic, the WHO reported significant differences in healthcare spending between low-income and high-income countries. ${ }^{26}$ During the pandemic, the economic impact of the pandemic may be more in some developing countries compared with resource-rich countries. ${ }^{28}$ Thus, income level serves as a good measure of baseline resources and health system vulnerability to a pandemic, and to what extent a non-COVID clinical service, such as transplantation, is affected.

We aimed to demonstrate that the collateral damage of the pandemic to a non-COVID clinical service varied by a country's income level. Many countries have wellestablished data repositories that capture transplant numbers and outcomes and then report them to the WHO's Global Observatory on Donation and Transplantation database. However, there is a lag of 1-2 years before this data becomes publicly available. Thus, we instead focused on some pragmatically identified measures of transplant activity and compared them by income level and cumulative COVID-19 incidence (CCI) of the region. We also aimed at comparing how physicians across different CCI and income-level perceived resources, finances and disease/patient-related factors as current and anticipated risks to their programmes.

\section{METHODS}

From June to September 2020, we conducted a multinational cross-sectional survey of transplant programmes (attached as a online supplemental file).

\section{Survey design}

The survey was designed using an iterative process by our team composed of transplant professionals and research methodologists. First, we pragmatically identified four simple measures that would successfully capture the transplant activity of a programme. These were (1) anticipating that the total number of transplantations, that is, transplant volume, will be $>75 \%$ of the programme's baseline volume; (2) performing transplantation/s during the initial months of the pandemic; (3) reporting declines in organ transplant offers from deceased donors when 
Table 1 Baseline characteristics of the transplant programme

Solid organ, n (\%)

\begin{tabular}{|c|c|}
\hline Heart & $44(8.6)$ \\
\hline Kidney & $285(55.6)$ \\
\hline Liver & $102(19.9)$ \\
\hline Lung & $42(8.2)$ \\
\hline Pancreas/Islet & $8(1.6)$ \\
\hline Multiple & $32(6.2)$ \\
\hline \multicolumn{2}{|c|}{ Age group of transplant recipients, $\mathrm{n}(\%)$} \\
\hline Adult only & $329(64.1)$ \\
\hline Paediatric only & $56(10.9)$ \\
\hline Both & $128(25.0)$ \\
\hline \multicolumn{2}{|c|}{ Baseline transplant volume ${ }^{*}, \mathrm{n}(\%)$} \\
\hline$<20$ & $142(27.6)$ \\
\hline $21-100$ & $231(45.1)$ \\
\hline$>100$ & $140(27.3)$ \\
\hline \multicolumn{2}{|l|}{ Health system, $n(\%)$} \\
\hline Public & $210(40.9)$ \\
\hline Private & $9(1.8)$ \\
\hline Mix of both & $293(57.1)$ \\
\hline Other & $1(0.2)$ \\
\hline \multicolumn{2}{|c|}{ Country's income levelt, n (\%) } \\
\hline Low income & $4(0.8)$ \\
\hline Lower-middle-income & $80(15.6)$ \\
\hline Upper-middle-income & $118(23.0)$ \\
\hline High income & $311(60.6)$ \\
\hline \multicolumn{2}{|c|}{ Cumulative COVID-incidence (CCI)‡, n (\%) } \\
\hline Low $(<2031 / M)$ & $176(34.3)$ \\
\hline Medium (2032-5400/M) & $190(37.0)$ \\
\hline High (>5400/M) & 147 (28.6) \\
\hline
\end{tabular}

*Self reported number of transplants performed annually prior to the pandemic.

†As defined by the World Bank at https://www.worldbank.org/. $\ddagger$ Per $1 \mathrm{M}$ population, calculated from 13 March 2020 to 15 July 2020 as reported by the Johns Hopkins COVID-19 Map, supplemented by covidindia.org. Reported in person per million population. For the USA, Canada, Australia, India and China, CCI was calculated by states/provinces, and for the rest by country.

compared with the prepandemic era and (4) having a ramp-down phase following the WHO announcement declaring the COVID-19 outbreak a pandemic.

We then used several best practices in survey creation to design our survey instrument. ${ }^{29-31}$ Following modifications and multiple rounds of revisions the final survey was created and then reviewed by the executive committee of The Transplantation Society. It was self-administered electronically using the Qualtrics XM platform. The survey was pilot tested using 10 participants who represented four different countries of varied income level.
Minor modifications to the survey were made, and these 10 responses were included in the data analysis. Additionally, the survey included sections on immunosuppression practices; results of which will be reported separately in a transplant specific journal.

\section{Recruitment}

Our recruitment goal was 500 different solid organ transplant programmes. This number was chosen keeping feasibility in mind and that the sample size would be large enough to detect differences between responses. One transplant centre can have up to five different solid organ transplant programmes (heart, kidney, liver, lung and pancreas/islet); hence, up to five participants from one centre could be contacted. We recruited a convenience sample of transplant physicians who were identified as key informants in their programmes using publicly available data (congress web pages, programme websites) and with the help of regional organisations and individuals (see the Acknowledgements section). We were able to obtain the names and contact emails of 1338 physicians from 80 different countries; of these 209 physicians had directly reached out to us with interest in participating in our study. Of the 1267 that were eligible and successfully contacted, 513 physicians from 71 different countries completed the survey for a response rate of $40.5 \%$. To ensure we achieved a heterogeneous sample, we had predetermined quotas of baseline characteristics of the programmes as outlined in figure 1; we successfully met all these quotas. ${ }^{32}$

\section{Exposures and main outcomes}

The main outcomes of interest were the four aforementioned measures of transplant activity. Exposures were the type of solid organ transplant, patient age group (adult or paediatric), baseline transplant volume, type of health system (public, private, or a mix of both), income level of the country, and CCI of the region where the programme was located. The first four variables were captured in the survey and were self-reported. Income level was assigned as per the 2020 World Bank Classification. ${ }^{33}$ CCI was calculated from 13 March 2020 to 15 July 2020, using the Johns Hopkins COVID-19 Map and supplemented with data reported from India. ${ }^{34}$ For the USA, Canada, Australia, India and China, CCI was calculated by state/province.

\section{Other outcomes}

Two other outcomes of interest were as follows. Earlier literature suggested that transplant programmes prioritise the need for an organ by individually assessing each patient's need for an organ as being urgent or emergent. Thus, we asked programmes to rate the likelihood of performing these types of transplants (urgent, emergent, non-urgent and living donor, if applicable) on a Likert scale of $1-5,1$ being unlikely and 5 being very likely. We also aimed to analyse and compare subjective perception of the risks to transplantation. We first conducted a needs assessment review of the literature and identified current and anticipated risks to transplantation. ${ }^{19}{ }^{36-45} \mathrm{We}$ diligently followed all real-time data related to COVID-19 


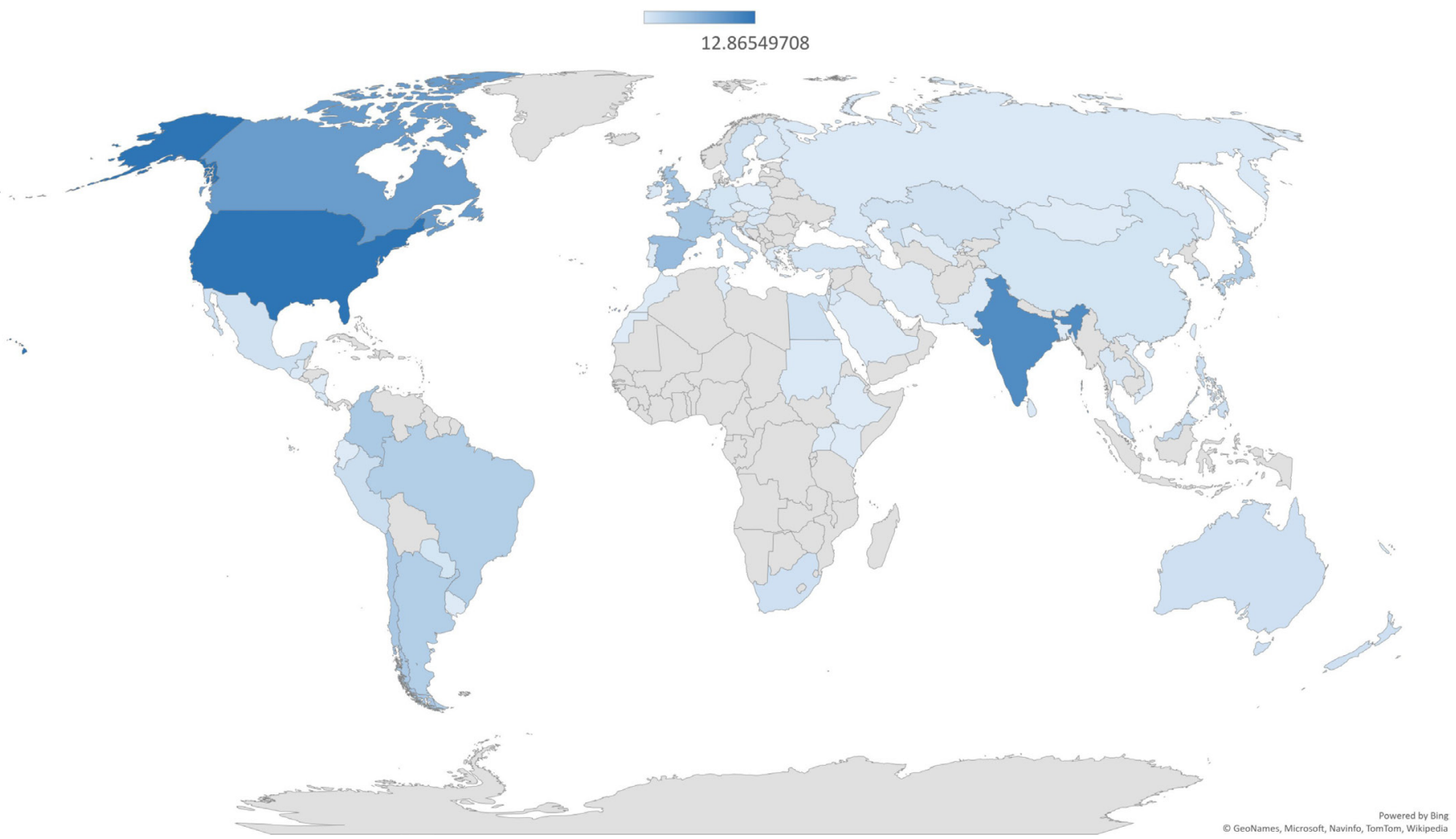

Figure 2 Geographical representation of the transplant programmes that participated in this study (depth of blue indicating the proportion of programmes from that country and grey indicating no representation).

that was being collectively captured by two major transplant orders on their online portals and web messaging services: the American Society of Transplantation and The Transplantation Society. We then constructed statements outlining these risks and asked respondents to rate their level of agreement on a Likert scale whether these statements were risks to their programmes. We segregated responses by the CCI and income level to compare the percentage of respondents in each sub-stratum of CCI and income level who agreed or strongly agreed with these statements.

\section{Data analysis}

Each transplant programme, hence, each survey response was treated as a unit of analysis. Descriptive statistics (frequencies, means) were used as appropriate to collectively describe survey responses. Fisher's exact tests were used for univariate comparison of four measures of transplant activity (anticipating transplant volume $>75 \%$ of the norm, performing no transplantation/s, maintaining prepandemic deceased donor offers, avoiding ramp-down of transplantation) across programme characteristics. Logistic regression was used to determine the association between programme characteristics (income level, CCI, organ type, patient age group, baseline transplant volume, health system) and these four measures in a multivariable framework. Bartlett's test of homogeneity of variances was used to examine variances in the likelihood of performing specific types of transplants. The response 'do not know' was excluded from the comparative analyses. All analyses were performed using Stata V.16.0/ MP for Linux and significance level using $\mathrm{p}<0.05$ was reported. All CIs are $95 \%$ CIs and are reported as per the method of Louis and Zeger. ${ }^{46}$

\section{Patient and public involvement statement}

This research was designed and performed without active patient or public involvement.

\section{RESULTS}

\section{Baseline characteristics}

Survey participants listed their primary roles as transplant surgeons $(28.8 \%)$, medical transplant specialists $(67.1 \%)$, administrators $(1.6 \%)$, infectious disease specialists $(0.6 \%)$ or others $(1.9 \%)$. The majority had been in practice for over 10 years; $5.5 \%<5$ years, $16.2 \%$ 5-10 years, $35.7 \% 11-20$ years and $42.5 \%>20$ years. The characteristics of the transplant programmes they represented are listed in table 1 and the location is illustrated in figure 2.

\section{Measures of transplant activity}

When compared with the norm, only $38 \%$ of transplant programmes anticipate that their transplant volume will be $>75 \%$ of the norm. However, $3.9 \%$ anticipate an increase in volume, due to an increase in donor referrals and closure of or refusal by other programmes in their region. Also, while $76.8 \%$ of the programmes were able to perform transplantation/s, only $24.9 \%$ reported being able to maintain pre-pandemic deceased donor offers 
Table 2 Measures of transplant programme activity during the early months of the pandemic

When compared with the norm, anticipated change to the programme's transplant volume, $\mathrm{n}(\%)$

$\begin{array}{lr}\text { No transplantations (0\%) } & 9(1.8) \\ <25 \% \text { of the norm } & 67(13.1) \\ 25 \%-50 \% \text { of the norm } & 103(20.1) \\ 50 \%-75 \% \text { of the norm } & 95(24.7) \\ 75 \%-100 \% \text { of the norm } & 80(15.6) \\ \text { No change (100\%) } & 20(3.9) \\ >100 \% \text { of the norm } & 12(2.3) \\ \text { Do not know } & 394(76.8) \\ \text { Programme performed transplantation/s, n (\%) } & 117(22.8) \\ \text { Yes } & 2(0.4) \\ \text { No } & 357(69.6) \\ \text { Do not know } & 89(17.3) \\ \text { When compared with the norm, change in deceased donor } \\ \text { offers to the programme during the pandemic, } \mathrm{n}(\%) \\ \text { Fewer/much fewer } & 39(7.6) \\ \text { No change } & 28(5.5) \\ \text { More/much more } & \\ \text { Do not know } & \end{array}$

Programme decided to ramp-down transplantation following the WHO announcement on 13 March 2020, n (\%)

\begin{tabular}{lc} 
Yes & $386(75.2)$ \\
No & $126(24.6)$ \\
Do not know & $1(0.2)$ \\
\hline
\end{tabular}

(no change or more offers) and $75.2 \%$ reported a rampdown phase (table 2).

\section{Measures of transplant activity by income level}

A significantly higher number of transplant programmes in high-income countries anticipate their transplant volume will be $>75 \%$ of the norm (high-income: $46.5 \%$, upper-middle-income: $\quad 31.6 \%$, low/lower-middleincome:21.7\%, $\mathrm{p}<0.001)$. This can be attributed to the fact that within these income brackets, high-income countries were more likely to perform transplantation/s $(86.8 \%, 58.5 \%, 67.9 \%, \mathrm{p}<0.001)$, maintain pre-pandemic deceased donor offers $(31.0 \%, 14.2 \%, 26.4 \%, \mathrm{p}<0.01)$, and avoid ramp-down of transplantation $(30.9 \%$ vs $19.7 \%$ vs $8.3 \%, \mathrm{p}<0.001)$, respectively.

\section{Logistic regression analysis of the measures of transplant activity}

Income level

In multivariable analyses, lower income level was negatively associated with all these measures of transplant activity. When compared with programmes from highincome countries, the odds of anticipating transplant volume to be $>75 \%$ of the norm was significantly lower for programmes in upper-middle-countries (adjusted OR
(aOR) $=0.47,95 \%$ CI 0.27 to 0.81 ) and for those in low/ lower-middle-income countries (aOR0.33, 95\% CI 0.16 to $0.67)$ ). Also, programmes in low/lower-middle-income countries had higher odds of being unable to perform transplantation/s (aOR 3.33, 95\% CI 1.49 to 7.43), but lower odds of maintaining prepandemic deceased donor offers (aOR $0.34,95 \%$ CI 0.16 to 0.71 ) and avoiding a ramp-down phase of transplantation (aOR 0.24, 95\% CI 0.09 to 0.64 ). For upper-middle-income countries, similar trends were noted, except for avoiding ramp-down of transplantation, which was not statistically different (aOR $0.63,95 \%$ CI 0.33 to 1.19 ) (table 3 ).

\section{Cumulative COVID-19 incidence}

The CCI of a particular region was not associated with any of these measures except for maintaining prepandemic deceased donor offers. When compared with transplant programmes from regions with low CCI, transplant programmes located in a region with medium CCI had lower odds of maintaining prepandemic deceased donor offers (aOR 0.38, 95\% CI 0.21 to 0.68). A programme in a region with high CCI also had lower odds for this measure, however, it did not reach statistical significance (aOR $0.55,95 \%$ CI 0.30 to 1.00 ) (table 3 ).

\section{Other exposures}

In adjusted analyses, adult vs paediatric programmes did not determine any of these four measures and neither did the type of health system. Kidney/pancreas transplant programmes and programmes that normally perform fewer transplants also appear to be disproportionately affected by the pandemic. (table 3 ).

\section{Types of transplants}

The mean likelihood score of performing an urgent transplantation was $3.98 \pm 1.57$, an emergent transplantation was $3.82 \pm 1.61$, a non-urgent transplantation was $3.25 \pm 1.66$, and living donor (if applicable) transplantations was $2.92 \pm 1.74$. Transplant programmes from low/lower-income and middle-income countries had a significantly lower likelihood of performing urgent but not emergent transplantations. Type of solid-organ programme and CCI were associated with the likelihood of performing both urgent and emergent transplantations (table 4).

\section{Risks to transplantation}

Overall, the top-rated current risk to transplantation was the increased utilisation of hospital resources $(66.3 \%)$. For anticipated risks, the top four rated statements were the burden of COVID-19 (76.2\%), lack of deceased donors $(64.5 \%)$, lack of a vaccine for COVID-19 (57.3\%) and resources being redirected to others $(54.4 \%)$. CCI did not seem to change the percentage of respondents that agreed with these statements being risks to their programmes, except for the burden of COVID-19 as a current and an anticipated risk. However, after segregating responses by income level of the country where the programme is located, these percentages were 
Table 3 The adjusted OR for the measures of transplant activity by programme characteristics (significant values in bold)

\begin{tabular}{|c|c|c|c|c|}
\hline & $\begin{array}{l}\text { Anticipating transplant } \\
\text { volume }>75 \% \text { of the } \\
\text { norm }\end{array}$ & $\begin{array}{l}\text { Performing no } \\
\text { transplantation }\end{array}$ & $\begin{array}{l}\text { Maintaining pre- } \\
\text { pandemic deceased } \\
\text { donor offers }\end{array}$ & $\begin{array}{l}\text { Avoiding } \\
\text { ramp-down of } \\
\text { transplantation }\end{array}$ \\
\hline \multicolumn{5}{|l|}{ Income level ${ }^{\star}$} \\
\hline High & Ref & Ref & Ref & Ref \\
\hline Upper-middle & $0.27 \mathbf{O . 4 7}_{0.81}$ & $2.163^{3.94_{7.17}}$ & 0.170 .320 .62 & $0.330 .63_{1.19}$ \\
\hline Low/lower-middle & $0.16 \mathbf{O . 3 3}_{0.67}$ & ${ }_{1.49} \mathbf{3 . 3 3}_{7.43}$ & $0.16 \mathbf{O . 3 4}_{0.71}$ & $0.09 \mathbf{0 . 2 4}_{0.64}$ \\
\hline \multicolumn{5}{|c|}{ Cumulative COVID-19 incidence† } \\
\hline$<20$ & Ref & Ref & Ref & Ref \\
\hline $20-100$ & $0.510 .85_{1.43}$ & $0.944^{1.78} 3.39$ & $0.21 \mathbf{0 . 3 8}_{0.68}$ & $0.330 .59_{1.07}$ \\
\hline$>100$ & 0.530 .921 .62 & $0.766^{1.52} 3.06$ & $0.300 .55_{1.00}$ & 0.330 .62 \\
\hline \multicolumn{5}{|c|}{ Type of solid-organ programme§ } \\
\hline Kidney/Pancreas & Ref & Ref & Ref & Ref \\
\hline Liver & 1.512 .474 .05 & 0.130 .270 .55 & $0.671 .17_{2.03}$ & $2.424 .26_{7.50}$ \\
\hline Heart & $0.551 .15_{2.41}$ & $0.07 \mathbf{0 . 1 7}_{0.50}$ & $0.230 .58_{1.47}$ & $2.204 .89_{10.85}$ \\
\hline Lung & 0.921 .924 .00 & $0.07 \mathbf{O . 2 3}_{0.76}$ & $0.41_{2.01}$ & $2.956 .44_{14.09}$ \\
\hline \multicolumn{5}{|l|}{ Age group of recipients } \\
\hline Adult programme & Ref & Ref & Ref & Ref \\
\hline Paediatric programme & $0.71^{1.41_{2.78}}$ & $0.380 .84_{1.88}$ & $0.480 .93_{2.26}$ & $0.91^{1.91}{ }_{3.99}$ \\
\hline \multicolumn{5}{|c|}{ Baseline transplant volumeł } \\
\hline Low & Ref & Ref & Ref & Ref \\
\hline Moderate & $0.480 .80_{1.34}$ & $0.13 \mathbf{O . 2 3}_{0.43}$ & $0.651 .18_{2.12}$ & 0.581 .051 .88 \\
\hline High & $0.420 .78_{1.47}$ & $0.06 \mathbf{0 . 1 2}_{0.25}$ & ${ }_{1.02} 2.01_{3.95}$ & $0.901 .89_{3.95}$ \\
\hline \multicolumn{5}{|l|}{ Health system } \\
\hline Mixed/private & Ref & Ref & Ref & Ref \\
\hline Public & $0.410 .64_{1.01}$ & $0.611^{1.07} 1.87$ & $0.410 .67_{1.11}$ & $0.390 .66_{1.11}$ \\
\hline
\end{tabular}

*As defined by the World Bank at https://www.worldbank.org/.

†Calculated from 13 March 2020 to 15 July 2020 as reported by the Johns Hopkins COVID-19 Map, supplemented by covidindia.org. Calculated in person per million population, we divided this variable into tertiles: low: <2031, medium: 2032-5400, high: >5400.

$\ddagger$ One response excluded as respondent picked 'do not know'.

$\S$ Excluding those who listed multiple organs as their scope of practice.

dramatically different. A much higher percentage of physicians from low/lower-middle-income countries identified resources, finances and disease/patient-related factors as risks to their programme. For statements related to finances, the percentage of respondents who identified these as risks were threefold to fivefold more in low-income/lower-middle-income countries (table 5).

\section{DISCUSSION}

In this global survey of 513 solid-organ transplant programmes from 71 different countries, we report that the collateral damage of the pandemic to transplantation varied by a country's baseline resources and health system vulnerability, as measured by the income level. Programmes from higher-income countries were more likely to anticipate that their transplant volume will be $>75 \%$ of the norm, and being able to perform transplantation/s, maintain prepandemic deceased donor offers and avoiding a ramp-down phase. Lower income level was negatively associated with all these measures of transplant activity even after adjusting for the CCI of the region. To our knowledge, this is the first global study to objectively demonstrate that transplant programmes in lower-income countries may have incurred more disruption from the pandemic even if their region's COVID-19 burden was low.

Earlier data suggested that most global cases of confirmed COVID-19 were seen in higher-income countries and lower-income countries may have been spared. ${ }^{34}$ However, lower-income countries are more vulnerable to disruptions of natural and manmade disasters, such as pandemics. ${ }^{24}$ Thus, many expressed concerns on the collateral damage of the pandemic to other clinical services in these countries. ${ }^{1-3}$ Most of these were commentaries or entailed modelling studies. Also, they pertained to infectious diseases that are endemic in these regions, 
Table 4 The likelihood of performing specific types of transplantations during the early months of pandemic rated on a scale of 1-5 ( 1 being unlikely and five being very likely) by programme characteristics (mean score and SD reported)*

\begin{tabular}{lllll}
\hline & Urgent & Emergent & Non-urgent & $\begin{array}{l}\text { Living donor } \\
\mathbf{2 . 9 2} \pm \mathbf{1 . 7 4}\end{array}$ \\
\hline Income level† & $\mathbf{3 . 9 8} \pm \mathbf{1 . 5 7}$ & $\mathbf{3 . 8 2} \pm \mathbf{1 . 6 1}$ & $\mathbf{3 . 2 5} \pm \mathbf{1 . 6 6}$ & $\mathrm{P}=0.002$ \\
\hline Low/lower-middle & $3.74 \pm 1.62$ & $\mathrm{P}=0.08$ & $\mathrm{P}=0.57$ & $\mathrm{P}=0.46$ \\
\hline Upper-middle & $3.33 \pm 1.76$ & $3.62 \pm 1.71$ & $2.66 \pm 1.56$ & $3.35 \pm 1.59$ \\
\hline High & $4.29 \pm 1.38$ & $3.26 \pm 1.72$ & $2.73 \pm 1.70$ & $2.53 \pm 1.71$ \\
\hline Cumulative COVID-19 incidenceł & $\mathrm{P}=0.001$ & $4.07 \pm 1.49$ & $3.60 \pm 1.58$ & $2.94 \pm 1.78$ \\
\hline Low & $3.71 \pm 1.66$ & $\mathrm{P}=0.02$ & $\mathrm{P}=0.90$ & $\mathrm{P}=0.66$ \\
\hline Medium & $3.88 \pm 1.63$ & $3.61 \pm 1.71$ & $3.13 \pm 1.69$ & $3.19 \pm 1.67$ \\
\hline High & $4.44 \pm 1.26$ & $3.67 \pm 1.65$ & $3.23 \pm 1.65$ & $2.74 \pm 1.79$ \\
\hline Type of solid organ & $\mathrm{P}<0.001$ & $4.23 \pm 1.37$ & $3.42 \pm 1.63$ & $2.80 \pm 1.75$ \\
\hline Kidney/pancreas & $3.71 \pm 1.67$ & $\mathrm{P}=0.02$ & $\mathrm{P}=0.47$ & $\mathrm{P}=0.42$ \\
\hline Liver & $4.29 \pm 1.42$ & $3.51 \pm 1.69$ & $3.02 \pm 1.69$ & $3.01 \pm 1.69$ \\
\hline Heart & $4.59 \pm 1.02$ & $4.23 \pm 1.40$ & $3.46 \pm 1.61$ & $2.86 \pm 1.85$ \\
\hline Lung & $4.38 \pm 1.27$ & $4.19 \pm 1.35$ & $3.89 \pm 1.40$ & $\mathrm{NA}$ \\
\hline Multiple & $4.03 \pm 1.62$ & $3.88 \pm 1.66$ & $3.52 \pm 1.67$ & $3.53 \pm 1.72$ \\
\hline Baseline transplant volume & $\mathrm{P}=0.93$ & $\mathrm{P}=0.66$ & $\mathrm{P}=0.99$ & $\mathrm{P}=0.83$ \\
\hline$<20$ & $3.92 \pm 1.57$ & $3.70 \pm 1.61$ & $3.11 \pm 1.67$ & $2.62 \pm 1.67$ \\
\hline $20-100$ & $4.00 \pm 1.56$ & $3.91 \pm 1.57$ & $3.23 \pm 1.66$ & $2.80 \pm 1.76$ \\
\hline$>100$ & $4.02 \pm 1.60$ & $3.78 \pm 1.68$ & $3.44 \pm 1.65$ & $3.33 \pm 1.72$ \\
\hline
\end{tabular}

*Bartlett's test of homogeneity of variances was used to examine variances across survey responses by these programme-level factors (do not know responses were excluded).

†As defined by the World Bank at https://www.worldbank.org/.

$\ddagger$ Calculated from 13 March 2015 to 15 July 2020 as reported by the Johns Hopkins COVID-19 Map, supplemented by covidindia.org. Calculated in person per million population, we divided this variable into tertiles: low: <2031, medium: 2032-5400, high: >5400.

NA, not applicable.

such as, HIV, tuberculosis and malaria. The differential impact of a specific clinical service across different regions are largely unexplored. We found only one survey study in the field of oncology, where authors reported that the severity of the pandemic on some aspects of cancer care were worse in centres from lower-income countries. ${ }^{47}$ However, they did not adjust for the COVID-19 burden of the region.

It is well recognised that social constructs, public health response and politics are playing a big role in determining COVID-19 trajectories and burden. We believe that CCI over the initial 4 months of the pandemic is a good measure of the COVID-19 burden as it considers variabilities in responses to the pandemic. Our study shows that it is not the COVID-19 burden per se, but the health system's vulnerability and baseline resources, as measured by the income level, that is, more important in determining measures of transplant activity. The field of solid organ transplantation requires the coordination of 'staff, space, stuff and systems'. ${ }^{48}$ Redirection of services and resources to COVID-19-related care was the morally and ethically right thing to do. ${ }^{811}$ We now objectively demonstrate that this has led to a significant more impact to solid organ transplantation in lower-income countries.
Recently, some data from lower-income countries did report that while patient and graft outcome of kidney transplants done during the COVID-19 pandemic were acceptable, the incidence of COVID-19 was $13.8 \%$ with a high case fatality ratio. ${ }^{21}$

Some other findings merit discussions. Similar to others, ${ }^{3644}$ we report that kidney transplant programmes are disproportionately affected by the pandemic. This is because due to the availability of dialysis, kidney transplantation is sometimes considered less urgent than heart, liver or lung transplantation. Second, transplantations are generally considered emergent if without them the patient will die in a few days. Thus, it is important to note that emergent transplantations had a similar likelihood of being performed across countries of all income level. Third, a higher proportion of physicians from lower-income countries perceived resources, finances and disease/patient-related factors as risks to their programmes. For example, screening methods for donors and recipients are well outlined in the literature ${ }^{9}$; yet, $47.0 \%$ of the programmes from low-income/lowermiddle-income countries agreed with the statement 'we do not know how best to screen recipients and donors' as being a risk to their programme. Thus, emerging 
Table 5 Percentage of respondents who agreed or strongly agreed with these statements as risks to their transplant programmes segregated by the cumulative COVID-19 incidence of the region and country's income level

\section{Cumulative COVID-19}

incidence*

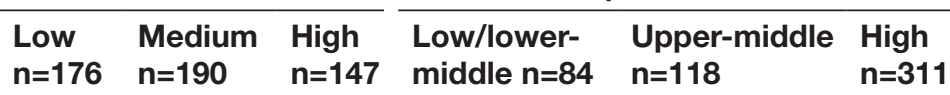

\section{Current risks (\% of agree/strongly agree responses)}

Resources

\begin{tabular}{|c|c|c|c|c|c|c|}
\hline There is a shortage of COVID-19 tests & 30.3 & 27.1 & 33.6 & 35.7 & 41.4 & 24.3 \\
\hline We do not have enough personal protective equipment & 20.6 & 18.5 & 21.1 & 26.2 & 26.5 & 15.8 \\
\hline $\begin{array}{l}\text { Transplant entails increased utilisation of hospital } \\
\text { resources }\end{array}$ & 61.9 & 71.4 & 65.3 & 79.8 & 65.8 & 63.0 \\
\hline ICUs in my area are overwhelmed & 41.5 & 53.4 & 47.6 & 66.7 & 62.4 & 37.0 \\
\hline \multicolumn{7}{|l|}{ Disease/patient } \\
\hline The burden of COVID-19 patients is high & 34.4 & 45.4 & 51.0 & 63.9 & 48.7 & 35.6 \\
\hline The sensitivity of the COVID-19 tests is suboptimal & 37.7 & 33.7 & 41.8 & 56.0 & 39.7 & 31.5 \\
\hline $\begin{array}{l}\text { We do not know how best to screen recipients and } \\
\text { donors }\end{array}$ & 27.4 & 22.9 & 30.6 & 47.0 & 29.3 & 20.3 \\
\hline \multicolumn{7}{|l|}{ Anticipated risks (\% of agree/strongly agree responses) } \\
\hline \multicolumn{7}{|l|}{ Resources } \\
\hline Being unable to travel to procure organs & 51.9 & 39.6 & 43.7 & 62.0 & 61.6 & 34.7 \\
\hline Lack of deceased donors & 70.7 & 66.5 & 63.9 & 78.9 & 81.7 & 59.0 \\
\hline Resources being redirected to others & 52.8 & 55.1 & 57.5 & 75.9 & 61.7 & 46.9 \\
\hline Administrative issues & 42.4 & 35.2 & 36.1 & 56.6 & 51.8 & 27.5 \\
\hline Lack of access to clinical trials & 27.8 & 20.8 & 15.3 & 42.5 & 25.0 & 14.7 \\
\hline \multicolumn{7}{|l|}{ Disease/patient } \\
\hline Lack of vaccine to COVID-19 & 63.8 & 56.7 & 56.2 & 82.9 & 66.7 & 49.8 \\
\hline The burden of COVID-19 & 67.2 & 84.2 & 81.0 & 91.6 & 87.1 & 69.9 \\
\hline Poor outcomes in transplant recipients with COVID-19 & 35.0 & 29.6 & 28.4 & 44.3 & 29.4 & 28.1 \\
\hline Lack of good quality evidence to treat COVID-19 & 54.0 & 45.9 & 46.2 & 68.7 & 52.7 & 42.0 \\
\hline Patient preference & 47.7 & 42.1 & 50.7 & 73.2 & 50.9 & 37.8 \\
\hline \multicolumn{7}{|l|}{ Finances } \\
\hline Financial issues -institution related & 30.9 & 27.6 & 26.5 & 46.4 & 45.7 & 16.9 \\
\hline Financial issues - patient related & 41.7 & 21.3 & 32.2 & 76.2 & 42.6 & 15.1 \\
\hline
\end{tabular}

*Calculated from 13 March 2020 to 15 July 2020 as reported by the Johns Hopkins COVID-19 Map, supplemented by covidindia.org. Calculated in person per million population, we divided this variable into tertiles: low: <2031, medium: 2032-5400, high: >5400.

†As defined by the World Bank at https://www.worldbank.org/.

ICU, Intensive care unit.

literature may not be universally applicable, and recommendations may not to be adapted to the local context. Leadership in each region is best suited to develop and shape contextually relevant interventions, while drawing on international partners as needed. ${ }^{3}$

A strength of this study is that we were able to mobilise transplant leadership from 71 different countries to take our survey and attain a good response rate amid a pandemic. We have identified four pragmatic and simple measures of transplant activity that have reliably captured the state of transplantation globally. These may serve as benchmarks for progress, improvements, and responses to intervention. Our work in transplantation serves as a surrogate for the impact of the pandemic on several other clinical services where access to timely care is necessary but was deprioritised, such as oncology and infectious diseases.

We, however, acknowledge the following limitations. The income level of a country is a good surrogate measure of a country's expenditure in health and the overall vulnerabilities of a healthcare system to a global pandemic. $^{23}{ }^{25-27}$ Yet, there are large variations among countries of similar incomes in healthcare spending, ${ }^{26}$ and we recognise that other health system factors, such 
as health financing and health workforce/capacity, may be relevant. We also acknowledge that the incidence of COVID-19 may be under-reported by many countries; however, the Johns Hopkins COVID-19 Map is the best data source for determining the COVID-19 burden and we supplemented it with data from a source from India. We could not obtain adequate representation from certain regions, such as East Asia and Africa, ${ }^{49} 50$ but our sample size was large enough to enable a comparative analysis and draw plausible conclusions. Many lower income countries rely more on living donation than deceased donation and we acknowledge that this was not accounted for. However, both deceased and living donation were impacted during the early days of the pandemic. The former because donor procurements were affected by availability of intensive care unit (ICU) beds, the latter as non-emergent surgeries were cancelled to accommodate for the COVID-19-related care. As with any survey study, our findings are at risk of subjective bias. However, as noted in table 2, most survey questions used in the present analysis had binary responses or were rated on a Likert scale; thus, the risk for subjective and acquiescence bias was low.

Regardless, our findings are extremely important as the COVID-19 pandemic has led to severe disruptions in the field of transplantation. Transplantation is a life-saving procedure in those with end-organ failure. The WHO's Task Force on Donation and Transplantation of Human Organs and Tissues reported that during the prepandemic period 17 transplantations were performed every hour and globally over 130000 solid-organ transplants were performed annually. ${ }^{51}$ This is estimated to represent less than $10 \%$ of the global need for a solid organ transplant, ${ }^{51}$ and the gap likely widened significantly during the pandemic. If all transplant programmes closed for 1 week only, 2856 fewer organs will be transplanted. Thus, the pool of patients waiting for an organ transplant and dying while waiting for one has likely increased significantly during the pandemic, more so in lower-income countries.

In conclusion, we report that most transplant programmes globally have incurred significant collateral damage from the COVID-19 pandemic. However, the impact of the pandemic was much more in lower income countries, independent of the CCI. Health systems in lower-income countries will likely need more effort to rebuild disrupted services and recuperate from the pandemic even if their COVID-19 burden was low. Our results can inform practice and policy to mitigate some of the ongoing effect of the pandemic on non-COVID medical fields.

\section{Author affiliations}

${ }^{1}$ Department of Medicine, Division of Nephrology, Multi-organ Transplant Program, Montreal, Québec, Canada

${ }^{2}$ Research Institute of the McGill University Health Centre, Montreal, Québec, Canada

${ }^{3}$ Department of Epidemiology, Johns Hopkins School of Public Health, Baltimore, Maryland, USA
${ }^{4}$ Department of Surgery, Johns Hopkins University, Baltimore, Maryland, USA ${ }^{5}$ Institute for Clinical Evaluative Sciences, Ottawa, Ontario, Canada ${ }^{6}$ The Ottawa Hospital Research Institute, Ottawa, Ontario, Canada

Acknowledgements We thank Dr Lorraine Bell, Dr Andrey Cybulsky, Patricia Hales, Dr Andrea Herrera-Gayol, Dr Rachel Massicotte, Dr Tomoko Takano and the executive committee of The Transplantation Society for reviewing our survey. We thank Sijia Wu, Anika Vankooten and Maricel Hope for their assistance with data collection. We would also like to thank the following individuals and organisations for helping us with the recruitment list: Dr Curie Ahn, Dr Helmut PD Arbogast, Dr Marcelo Barrios, Dr Abdelhadi AL Breizat, Dr Mirela Bušić, Robert Caruso, Dr Toby Coates, Dr Beatriz Domínguez-Gil, Dr Hiroto Egawa, Dr Susumu Eguchi, Dr Maria Gerbase de Lima, Dr Rodrigo López Falcony, Dr John Forsyth, Dr Gabriel Gondolesi, Dr Mehmet Haberal, Dr Eric Hooste, Dr Tania Imran, Dr Jong Cheol Jeong, Agustín Iturregui, Dr Refaat Kamel, Dr Alvaro Kompatzki, Dr Dirk Kuypers, Dr Vivek Kute, Dr Alexandre Loupy, Dr Maggie Ma, Dr Nancy Kwan Man, Dr Maria A. Matamoros, Dr Raul Mizraji, Dr Alejandro Niño-Murcia, Nieves Piaggio, Dr Helen Pilmore, Dr Marlies Reinders, Dr Adam Remport, Dr Gamal Saadi, Dr Dennis P. Serrano, Professor Dra. Idalina Stanley, Dr Anikka Tibell, Dr Luciola Vasquez Flores, Dr Haibo Wang, Dr Karl Martin Wissing, Dr Aysegul Yesilkaya, Dr Shiong Shiong Yew and Dr Bengt von Zur-Mühlen. The organisations are as follows: the Belgian Transplantation Society, the Brazilian Association for Organ Transplantation, the Chilean Society of Transplantation, the Colombian Organ Transplantation Association, the Mexican Society of Transplantation, the Paraguayan Transplant Society, and the Swedish Transplant Society. Finally, we thank the following orders and organisation for supporting/endorsing our study: African Society of Organ Transplantation, Asian Society of Transplantation, Canadian Donation and Transplantation Research Program, China Organ Transplant Response System, European Society of Transplantation, Indian Society of Transplantation, International Pancreas and Islet Transplant Association, International Pediatric Transplant Association, International Society for Heart and Lung Transplantation, International Society of Nephrology, Japan Society of Transplantation, Korean Society of Transplantation, Middle East Society for Organ Transplantation, National Transplant Organisation of Spain, The Transplantation Society, Transplantation Society of Australia and New Zealand and Transplant Society of Latin America and the Caribbean.

Contributors SS: conceived and designed the work, acquired the data; analysed and interpreted the data; drafted the manuscript; approved the final version. BB and DLS: helped design the work; involved with data analysis, and interpretation; critically revised the manuscript, approved the final version. TP-YC and AM: involved with data analysis and interpretation; critically revised the manuscript, approved the final version. KT: helped design the work; involved with data interpretation; critically revised the manuscript, approved the final version. MC: conceived and designed the work; involved with data collection; critically revised the manuscript, approved the final version; responsible for the overall content as the guarantor.

Funding The authors have not declared a specific grant for this research from any funding agency in the public, commercial or not-for-profit sectors.

Map disclaimer The inclusion of any map (including the depiction of any boundaries therein), or of any geographic or locational reference, does not imply the expression of any opinion whatsoever on the part of BMJ concerning the legal status of any country, territory, jurisdiction or area or of its authorities. Any such expression remains solely that of the relevant source and is not endorsed by BMJ. Maps are provided without any warranty of any kind, either express or implied.

Competing interests DLS receives speaking honoraria from Sanofi and Novartis. SS has received an education grant from Amgen Canada. The rest of the authors have no disclosures.

Patient consent for publication Not applicable.

Ethics approval This study was approved by the Research Ethics Board at the McGill University Health Centre, more precisely its Cells, Tissues, Genetics and Qualitative research panel. (Study ID: 2021-6709).

Provenance and peer review Not commissioned; externally peer reviewed.

Data availability statement Data are available on reasonable request. Data sharing requests for deidentified data reported in this article will be considered upon written request to the corresponding author for up to 36 months following publication of this work. Data will be available subject to a written proposal, approval by an independent review committee and a signed data-sharing agreement.

Supplemental material This content has been supplied by the author(s). It has not been vetted by BMJ Publishing Group Limited (BMJ) and may not have been 
peer-reviewed. Any opinions or recommendations discussed are solely those of the author(s) and are not endorsed by BMJ. BMJ disclaims all liability and responsibility arising from any reliance placed on the content. Where the content includes any translated material, BMJ does not warrant the accuracy and reliability of the translations (including but not limited to local regulations, clinical guidelines, terminology, drug names and drug dosages), and is not responsible for any error and/or omissions arising from translation and adaptation or otherwise.

Open access This is an open access article distributed in accordance with the Creative Commons Attribution Non Commercial (CC BY-NC 4.0) license, which permits others to distribute, remix, adapt, build upon this work non-commercially, and license their derivative works on different terms, provided the original work is properly cited, appropriate credit is given, any changes made indicated, and the use is non-commercial. See: http://creativecommons.org/licenses/by-nc/4.0/.

\section{ORCID iDs}

Shaifali Sandal http://orcid.org/0000-0003-1941-0598

Marcelo Cantarovich http://orcid.org/0000-0002-4766-3333

\section{REFERENCES}

1 Jewell BL, Mudimu E, Stover J, et al. Potential effects of disruption to HIV programmes in sub-Saharan Africa caused by COVID-19: results from multiple mathematical models. Lancet HIV 2020;7:e629-40.

2 Hogan AB, Jewell BL, Sherrard-Smith E, et al. Potential impact of the COVID-19 pandemic on HIV, tuberculosis, and malaria in low-income and middle-income countries: a modelling study. Lancet Glob Health 2020;8:e1132-41.

3 Kelley M, Ferrand RA, Muraya K, et al. An appeal for practical social justice in the COVID-19 global response in low-income and middleincome countries. Lancet Glob Health 2020;8:e888-9.

4 Loupy A, Aubert O, Reese PP, et al. Organ procurement and transplantation during the COVID-19 pandemic. Lancet 2020;395:e95-6.

5 Boyarsky BJ, Werbel WA, Durand CM, et al. Early national and center-level changes to kidney transplantation in the United States during the COVID-19 epidemic. Am J Transplant 2020;20:3131-9.

6 Domínguez-Gil B, Coll E, Fernández-Ruiz M, et al. COVID-19 in Spain: transplantation in the midst of the pandemic. Am J Transplant 2020;20:2593-8

7 DeFilippis EM, Sinnenberg L, Reza N, et al. Trends in US heart transplant waitlist activity and volume during the coronavirus disease 2019 (COVID-19) pandemic. JAMA Cardiol 2020;5:1048-52.

8 Stock PG, Wall A, Gardner J, et al. Ethical issues in the COVID era: doing the right thing depends on location, resources, and disease burden. Transplantation 2020;104:1316-20.

9 Kumar D, Manuel O, Natori Y, et al. COVID-19: a global transplant perspective on successfully navigating a pandemic. Am J Transplant 2020;20:1773-9.

10 Boyarsky BJ, Po-Yu Chiang T, Werbel WA, et al. Early impact of COVID-19 on transplant center practices and policies in the United States. Am J Transplant 2020;20:1809-18.

11 Kute V, Ramesh V, Shroff S. Benefit to few versus risk to many: an ethical dilemma during coronavirus disease 2019 pandemic for deceased-donor organ transplant in a resource-limited developing country. Exp Clin Transplant 2020.

12 Wu Z, McGoogan JM. Characteristics of and important lessons from the coronavirus disease 2019 (COVID-19) outbreak in China: summary of a report of 72314 cases from the Chinese center for disease control and prevention. JAMA 2020;323:1239-42.

13 Fernández-Ruiz M, Andrés A, Loinaz C, et al. COVID-19 in solid organ transplant recipients: a single-center case series from Spain. Am J Transplant 2020;20:1849-58.

14 Kates O, Fisher C, Lease E. COVID-19 in SOT University of Washington registry weekly update: 210 cases 2020 .

15 Fishman JA, Grossi PA. Novel Coronavirus-19 (COVID-19) in the immunocompromised transplant recipient: \#Flatteningthecurve. Am J Transplant 2020;20:1765-7.

16 Alberici F, Delbarba E, Manenti C, et al. Management of patients on dialysis and with kidney transplantation during the SARS-CoV-2 (COVID-19) pandemic in Brescia, Italy. Kidney Int Rep 2020;5:580-5.

17 Dholakia S, Valentine H. International COVID-19 solid organ transplant registry, 2020.

18 Fishman JA. The immunocompromised transplant recipient and SARS-CoV-2 infection. J Am Soc Nephrol 2020;31:1147-9.

19 Angelico R, Trapani S, Manzia TM, et al. The COVID-19 outbreak in Italy: initial implications for organ transplantation programs. Am J Transplant 2020;20:1780-4.
20 Lentine KL, Vest LS, Schnitzler MA, et al. Survey of US living kidney donation and transplantation practices in the COVID-19 era. Kidney Int Rep 2020;5:1894-905.

21 Jha PK, Yadav DK, Siddini V, et al. A retrospective multi-center experience of renal transplants from India during COVID-19 pandemic. Clin Transplant 2021;35.

22 Ji Y, Ma Z, Peppelenbosch MP, et al. Potential association between COVID-19 mortality and health-care resource availability. Lancet Glob Health 2020;8:e480.

23 Stewart R, El-Harakeh A, Cherian SA. Evidence synthesis communities in low-income and middle-income countries and the COVID-19 response. Lancet 2020;396:1539-41.

24 Rentschler J. Why resilience matters - the poverty impacts of disasters. The World Bank, global facility for disaster reduction and recovery and office of the chief economist sustainable development network, 2013. Available: https://documents1.worldbank.org/ curated/en/613071468159301542/pdf/WPS6699.pdf [Accessed Jul 2021].

25 Marmot M. The influence of income on health: views of an epidemiologist. Health Aff 2002;21:31-46.

26 Global Spending on Health. A world in transition. Geneva: World Health Organization, 2019.

27 Walker PGT, Whittaker C, Watson OJ, et al. The impact of COVID-19 and strategies for mitigation and suppression in low- and middleincome countries. Science 2020;369:413-22.

28 Maliszewska, Aaditya; van der Mensbrugghe, Dominique. The potential impact of COVID-19 on GDP and trade: a preliminary assessment. Policy research working paper; No. 9211. Washington, DC: World Bank, 2020.

29 Boynton PM, Greenhalgh T. Selecting, designing, and developing your questionnaire. BMJ 2004;328:1312-5.

30 Oppenheim AN. Questionnaire design, interviewing and attitude measurement. London; New York: Pinter Publishers, 1992.

31 Oppenheim A. Questionnaire design, interviewing and attitude measurement. Bloomsbury Academic, 2000.

32 Encyclopedia of survey research methods 2008.

33 World bank country and lending groups, 2020. Available: https:// datahelpdesk.worldbank.org/knowledgebase/articles/906519-worldbank-country-and-lending-groups [Accessed 1 Sep 2020].

34 Coronavirus COVID-19 global cases by the center for systems science and engineering, 2020. Available: https://coronavirus.jhu. edu/map.html [Accessed Sep 2020].

35 Open repository of all COVIDIndia.org's historical data, 2020. Available: https://covidindia.org/\# [Accessed 15 Oct 2020].

36 Martino F, Plebani M, Ronco C. Kidney transplant programmes during the COVID-19 pandemic. Lancet Respir Med 2020;8:e39.

37 Elens L, Langman LJ, Hesselink DA, et al. Pharmacologic treatment of transplant recipients infected with SARS-CoV-2: considerations regarding therapeutic drug monitoring and drug-drug interactions. Ther Drug Monit 2020;42:360-8.

38 Russell B, Moss C, George G, et al. Associations between immunesuppressive and stimulating drugs and novel COVID-19-a systematic review of current evidence. Ecancermedicalscience 2020;14:1022.

39 Fix OK, Hameed B, Fontana RJ, et al. Clinical best practice advice for hepatology and liver transplant providers during the COVID-19 pandemic: AASLD expert panel consensus statement. Hepatology 2020;72:287-304.

40 Wall AE, Pruett T, Stock P, et al. Coronavirus disease 2019: utilizing an ethical framework for rationing absolutely scarce health-care resources in transplant allocation decisions. Am J Transplant 2020;20:2332-6.

41 Transplantation ASo. Outstanding questions in transplantation research, 2020.

42 Guidance on coronavirus disease 2019 (COVID-19) for transplant clinicians, 2020. Available: https://tts.org/tid-about/tid-presidentsmessage/23-tid/tid-news/657-tid-update-and-guidance-on-2019novel-coronavirus-2019-ncov-for-transplant-id-clinicians [Accessed 20 Apr 2020].

43 Fishman JA, Grossi PA. Novel Coronavirus-19 (COVID-19) in the immunocompromised transplant recipient: \#Flatteningthecurve. Am J Transplant 2020.

44 Kumar D, Manuel O, Natori Y, et al. COVID-19: a global transplant perspective on successfully navigating a pandemic. Am J Transplant 2020;20:1773-9.

45 Ho QY, Chung SJ, Gan VHL, et al. High-immunological risk living donor renal transplant during the COVID-19 outbreak: uncertainties and ethical dilemmas. Am J Transplant 2020;20:1949-51.

46 Louis TA, Zeger SL. Effective communication of standard errors and confidence intervals. Biostatistics 2009;10:1-2. 
47 Jazieh AR, Akbulut H, Curigliano G, et al. Impact of the COVID-19 pandemic on cancer care: a global collaborative study. JCO Glob Oncol 2020;6:1428-38.

48 Bucuvalas J, Lai JC. Unforeseen consequences of the COVID pandemic. Am J Transplant 2020;20:2973-4.

49 Lau H, Khosrawipour T, Kocbach P, et al. Evaluating the massive underreporting and undertesting of COVID-19 cases in multiple global epicenters. Pulmonology 2021;27:110-5.
50 Biswas RK, Afiaz A, Huq S. Underreporting COVID-19: the curious case of the Indian subcontinent. Epidemiol Infect 2020;148:e207.

51 Global observatory on donation and transplantation., 2020. Available: http://www.transplant-observatory.org/download/2017-activity-datareport/ [Accessed 24 Apr 2020]. 